\title{
Extended benefits of TAVR in young patients with low- intermediate risk score: proceed with care
}

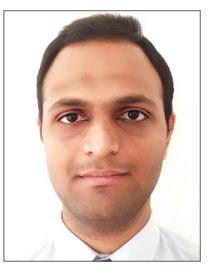

\author{
Rajkumar Doshi, MD, MPH \\ Department of Cardiology, North Shore University Hospital, Manhasset, NY, USA
}

I read with great interest the article "In-hospital outcomes after transcatheter or surgical aortic valve replacement in younger patients less than 75 years old: a propensity-matched comparison" by Eggebrecht et $\mathrm{al}^{1}$. The authors revealed similar in-hospital mortality and stroke rates in the propensity score-matched transfemoral-transcatheter aortic valve replacement (TF-TAVR) and surgical aortic valve replacement (SAVR) patients. However, need for permanent pacemaker rates were fourfold higher with TF-TAVR. This study is of significant importance since the indications for TAVR have been increasing following the SURTAVI trial ${ }^{2}$.

I have a few concerns regarding this study. First, more lowrisk patients were included in the SAVR group (95\% versus $55 \%$ ) prior to the matching. Second, after propensity score matching, the standardised difference was $78.7 \%$ between the groups $(p<0.001)$ with almost double in the TF-TAVR group. This could be one of the reasons for comparable mortality with TF-TAVR and SAVR in this study. Third, other routes for performing TAVR have been expanding which may include direct-aortic, subclavian, or carotid approach. These alternatives could be associated with higher success rates and lower complication rates ${ }^{3}$. Finally, the type of valve is not mentioned in this article. Valve design has been improving to reduce paravalvular leak post $\mathrm{TAVR}^{4}$. Additionally, the prevalence of the anatomy of the valve (bicuspid or tricuspid) is not described in this paper. Although the prevalence of bicuspid valves is more common in these young patients ${ }^{5}$, the decision to perform TAVR should be carefully weighed, keeping all the benefits and risks in mind.

In conclusion, TAVR techniques are improving with its increasing indications. Young patients may receive benefits from TAVR; however, we need to determine best practices in relation to the benefits for our patients based on the observational database until more robust randomised control trial results are presented.

\section{Conflict of interest statement}

The author has no conflicts of interest to declare.

\section{References}

1. Eggebrecht $\mathrm{H}$, Bestehorn $\mathrm{K}$, Rassaf $\mathrm{T}$, Bestehorn $\mathrm{M}$, Voigtländer T, Fleck E, Schächinger V, Schmermund A, Mehta RH. In-hospital outcomes after transcatheter or surgical aortic valve replacement in younger patients less than 75 years old: a propensity-matched comparison. EuroIntervention. 2018;14:50-7.

2. Reardon MJ, Van Mieghem NM, Popma JJ, Kleiman NS, Sondergaard L, Mumtaz M, Adams DH, Deeb GM, Maini B, Gada H, Chetcuti S, Gleason T, Heiser J, Lange R, Merhi W, Oh JK, Olsen PS, Piazza N, Williams $M$, Windecker $\mathrm{S}$, Yakubov SJ, Grube E, Makkar R, Lee JS, Conte J, Vang E, Nguyen H, Chang Y, Mugglin AS, Serruys PW, Kappetein AP; SURTAVI Investigators. Surgical or Transcatheter Aortic-Valve Replacement in Intermediate-Risk Patients. $N$ Engl J Med. 2017;376:1321-31.

3. Petronio AS, De Carlo M, Bedogni F, Marzocchi A, Klugmann S, Maisano F, Ramondo A, Ussia GP, Ettori F, Poli A, Brambilla N, Saia F, De Marco F, Colombo A. Safety and efficacy of the subclavian approach for transcatheter aortic valve implantation with the CoreValve revalving system. Circ Cardiovasc Interv. 2010;3:359-66.

4. Pilgrim T, Lee JKT, O’Sullivan CJ, Stortecky S, Ariotti S, Franzone A, Lanz J, Heg D, Asami M, Praz F, Siontis GCM, Vollenbroich R, Räber L, Valgimigli M, Roost E, Windecker S. Early versus newer generation devices for transcatheter aortic valve implantation in routine clinical practice: a propensity score matched analysis. Open Heart. 2018;5:e000695.

5. Lewin MB, Otto CM. The bicuspid aortic valve: adverse outcomes from infancy to old age. Circulation. 2005;111:832-4. 